\title{
Pengaruh Tekanan Ketaatan, Materialitas dan Risiko Audit terhadap Ketepatan Judgment Auditor pada Kantor Akuntan Publik di Sumatera Utara
}

\author{
Agustina \\ Politeknik Kutaraja, Kota Banda Aceh, Indonesia.
}

\begin{abstract}
Abstrak. Tujuan Penelitian ini adalah untuk mengetabui pengarub tekanan ketaatan, materialitas, dan risiko audit terbadap ketetpan judgment auditor pada Kantor Akuntan Publik di Sumatera Utara. Analisa ini berdasarkan data yang diperoleb dari 45 responden yaitu auditor yang mempunyai jabatan auditor senior dan auditor junior pada kantor Akuntan Publik di Sumatera Utara dengan cara mengedarkan kuesioner. Penelitian ini merupakan penelitian sensus. Data yang dipakai adalab data primer, yang diperoleh secara langsung dari subjek penelitian dalam bentuk persepsi responden dengan cara mengedarkan daftar pertanyaan dalam bentuk. kuesioner kepaa responden. Dari jumlah kuesioner yang diedarkan kepada responden sebanyak, 52 lembar, hanya 45 lembar yang kembali dengan tingkat pengembalian mencapai 86,53\%. Selanjutnya analisis data dalam penelitian ini menggunakan regresii linear berganda (multiple linear regression) yang diolab dengan menggunakan program komputer Statistical Product and Service Solution (SPSS) ver 15.0. Hasil penelitian menunjukkan babwa baik secara simultan maupun parsial tekanan ketaat, materialitas, dan risiko audit berpengaruh terbadap ketepatan judgment auditor pada kantor Akuntan Publik di Sumatera Utara. Hal ini membuktikan bahwa semakin tinggi tekanan ketaatan, materialitas dan risiko audit yang dimilki oleh auditor, maka semakin tinggi pula judgment auditor.
\end{abstract}

Kata kunci: Tekanan Ketaatan, Materialitas, Risiko Audit, dan Judgment Auditor.

\begin{abstract}
The purpose of this study was to determine the effect of compliance, materiality, and audit risk on the judgment of the auditor's judgment on the Public Accounting Firm in North Sumatra. This analysis is based on data obtained from 45 respondents, namely auditors who have senior auditor positions and junior auditors at the Public Accountants office in North Sumatra by distributing questionnaires. This research is census research. The data used is primary data, which is obtained directly from the research subject in the form of respondents' perceptions by circulating the questionnaire in the form of a questionnaire to the respondent. From the number of questionnaires circulated to respondents as many as 52 sheets, only 45 sheets returned with a rate of return reaching $86.53 \%$. Furthermore, the data analysis in this study used multiple linear regression which was processed using a computer program Statistical Product and Service Solution (SPSS) ver 15.0. The results of the study showed that both simultaneously and partially obedient pressure, materiality, and audit risk had an effect on the accuracy of the auditor's judgment at the Public Accounting Firm in North Sumatra. This proves that the higher the pressure of obedience, materiality and audit risk possessed by the auditor, the higher the auditor's judgment.
\end{abstract}

Keywords: Pressure of obedience, Materiality, Audit Risk, and Auditor Judgment.

*Corresponding author. Email: agustina@poltekkutaraja.ac.id

DOI: https://doi.org/10.35870/emt.v4i2.152

Received: 24 September 2020, Revision: 17 October 2020, Accepted: 30 October 2020

Print ISSN: 2579-7972; Online ISSN: 2549-6204.

Copyright@ @2020. Published by Lembaga Otonom Lembaga Informasi dan Riset Indonesia (KITA INFO dan RISET).

114 | Jurnal Ekonomi dan Manajemen Teknologi Vol. 4 | No. 2 | 2020 


\section{Pendahuluan}

Banyak masalah yang terjadi pada berbagai kasus bisnis yang ada pada saat ini yang melibatkan profesi auditor (Giri, 2010). Auditor dituntut untuk memberikan suatu jasa yang berkualitas. Laporan hasil yang berisi pernyataan pendapat auditor tidak terlepas dari judgment (pertimbangan) temuan penting yang mengandung unsur ketidakpastiaan (Thahir, 2016). Auditor sering menghadapi banyak tekanan dalam penugasan audit yang dapat mempengaruhi independensi sehingga judgment yang dihasilkannya tidak valid dan berkualitas (Akadiyantor, 2004). Meyer dan Rigsby (2001) mengemukakan bahwa seorang auditor dalam melakukan tugasnya membuat audit judgment di pengaruhi baik bersifat teknis maupun non teknis. Aspek perilaku individu, sebagai salah satu faktor yang banyak mempengaruhi pembuatan audit judgment (Yustrianthe, 2012), sekarang ini semakin banyak menerima perhatian dan praktisi akuntansi dari akademisi. Namun demikian meningkatnya perhatian tersebut tidak diimbangi dengan pertumbuhan penelitian di bidang akuntansi keprilakuan dimana dalam banyak penelitian tidak menjadi fokus utama. Cara pandang auditor dalam menanggapi informasi berhubungan dengan tanggung jawab dan risiko audit yang akan dihadapi oleh auditor sehubungan dengan judgment yang dibuatnya. Literatur dalam bidang akuntansi telah merefleksikan dan mengakui pentingnya mengavaluasi pengaruh pressure (tekanan) yang dihasilkan dari dalam organisasi terhadap sikap, keinginan, dan perilaku auditor.

Skandal fraud dalam laporan keuangan perusahaan besar yang terjadi pada Satyam melibatkan kantor akuntan publik (KAP) besar seperti Price Waterhouse India. PwC mengumumkan bahwa laporan auditnya berpotansi tidak akurat dan tidak reliable karena dilakukan berdasarkan informasi yang diperoleh dari maajemen Satyam. Institusi akuntan di India ICAI, meminta PwC memberikan jawaban resmi dalam 21 hari terkait skandal Satyam (Novianti dan Adiati, 2009). Di Indonesia juga terjadi hal yang sama seperti yang dilaporkan oleh BAPEPAM yaitu kasus PT. Kimia Farma Tbk, yakni terjadinya overstated pada laba bersih per 31 desember 2001 (Jamilah et al, 2007), dan kasus ini laporan keuangan auditan PT. Telkom tidak diakui oleh SEC (pemegang otoritas pasar modal di Amerika Serikat). Peristiwa ini mengharuskan dilakukannya audit ulang terhadap PT. Telkom oleh KAP yang lain (Trisnaningsih, 2007). Sehingga dengan terjadinya kasusu seperti ini dapat menjadi pembelajaran bersama bagi perkembangan profesi auditor di Indonesia dengan lebih meningkatkan kinerja mereka.

\section{Literature Review}

\section{Judgment Auditor}

Menurut Siegel dan Marconi (1989), judgment adalah perilaku yang paling berpengaruh dalam mempersepsikan situasi, dimana faktor utama yang mempengaruhi adalah materialitas dan apa yang kita yakini sebagai kebenaran. Akuntan pemeriksa yang berpengalaman membuat judgment lebih baik dalam tugas-tugas profesional ketimbang akuntan pemeriksa yang belum berpengalaman (Herliansyah \& Ilyas, 2006). Hal ini dipertegas oleh Yendrawati \& Mukti (2015) yang menemukan bahwa pengalaman audit yang dipunyai auditor ikut berperan dalam menentukan pertimbangan yang diambil.

\section{Tekanan Ketaatan}

Menurut Kamus Besar Bahasa Indonesia (2005), tekanan memiliki makna: keadaan (hasil) kekuatan menekan; desakan yang kuat; paksaan; keadaaan tidak menyenangkan yang umumnya merupakanbeban batin. Sedangkan patuh memiliki makna; suka menurut (perintah,dsb); taat (kepada perintah, aturan, dsb); berdisplin. Kepatuhan bersifat patuh; ketaatan. Sementara menurut Jamilah et al (2007), tekanan ketaatan adalah tekanan yang diterima oleh auditor dalam menghadapi atasan dan klien untuk melakukan tindakan menyimpang dari standar etika.

\section{Materialitas \\ Materialitas merupakan besarnya nilai yang dihilangkan atau salah saji informasi akuntansi, yang dilihat dari keadaan yang melingkupinya, dapat mengakibatkan perubahan atas atau pengaruh terhadap pertimbangan orang yang meletakkan kepercayaan terhadap informasi tersebut, karena adanya penghilangan atau salah saji itu (Mulyani, 2002). Hal itu mengharuskan auditor untuk mempertimbangkan keadaan yang berkaitan dengan entitas dan kebutuhan informasi pihak yang akan meletakkan}


kepercayaan atas laporan keuangan auditan (Fanny \& Saputra, 2005).

\section{Risiko Audit}

Risiko audit (audit risk) merupakan Risiko kesalahan auditor dalam memberikan pendapat wajar tanpa pengecualian atas laporan keuangan yang salah saji secara material (Ariningsih \& Mertha, 2017). Risiko bisnis (business risk) merupakan risiko dimana auditor akan menderita kerugian atau merugikan dalam melakukan praktik profesinya akibat proses pengadilan atau penolakan publik dalam hubungannya dengan audit (Rajagukguk, 2017). Risiko audit merupakan risiko yang timbul karena auditor tanpa disadari tidak memodifikasi pendapatnya sebagaimana semestinya (Handayani, Yusralaini, \& Natariasari, 2016), atas suatu laporan keuangan yang mengandung salah material (Agoes, 2004). Pengguna laporan keuangan merupakan unsur utama dalam risiko bisnis (Adam \& Suzan, 2015). Untuk menentukan tingkat kepastian yang diperlukan, auditor terlebih dahulu harus mengidentifikasi pengguna potensial laporan keuangan (Danny, 2015). Jumlah pengguna laporan keuangan yang lebih besar akan meningkatkan risiko bisnis dan dapat meningkatkan tingkat kepastian yang diinginkan auditor (Yenni, 2017; Hamdani dkk, 2018).

Tantangan akhir dari suatu audit adalah bahwa auditor tidak dapat memeriksa semua bukti yang berkaitan dengan setiap asersi untuk setiap saldo akun dan golongan transaksi (Lubis \& Dewi, 2002. Model risiko audit menjadi pedoman para auditor dalam pengumpulan bukti audit, sehingga auditor dapat mencapai tingkat keyakinan yang memadai yang diinginkan.

\section{Kerangka Teoritis}

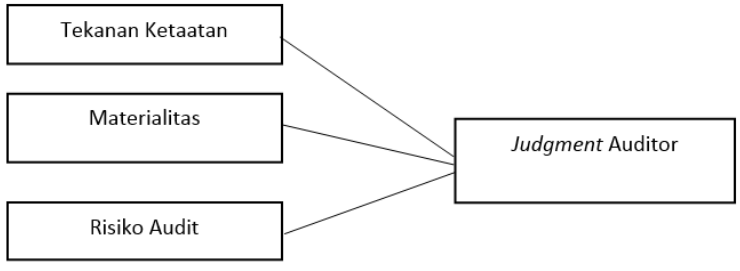

Gambar 1. Kerangka Teoritis

\section{Kerangka Teoritis}

$\mathrm{H}_{1}$ : Tekanan ketaatan, materialitas dan risiko audit berpengaruh secara simultan terhadap ketepatan judgment auditor pada Kantor Akuntan Publik di Sumatera Utara.

$\mathrm{H}_{2}$ : Tekanan ketaatan berpengaruh terhadapa ketepatan judgment auditor pada Kantor Akuntan Publik di Sumatera Utara

$\mathrm{H}_{3}$ : Materialitas berpengaruh terhadap ketetapan judgment auditor pada Kantor Akuntan Publik di Sumatera Utara

$\mathrm{H}_{4}$ : Risiko audit berpengaruh terhadap ketetpan judgment auditor pada Kantor Akuntan Publik di Sumatera Utara

\section{Metodologi Penelitian}

\section{Populasi Penelitian}

Populasi adalah keseluruhan objek peneltian (Arikunto, 2006:130). Adapun yang menjadi populasi dalam penelitian ini adalah auditor yang bekerja di Kantor Akuntan Publik di Sumatera Utara. Jumlah keseluruhan populasi 52 auditor. Teknik pengambilan populasi menggunakan metode sensus.

\section{Data dan Teknik Pengumpulan Data}

Data dalam penelitian ini terdiri dari data primer yaitu data yang di ambil langsung dari sumbernya atau belum melalui proses pengumpulan pihak lain atau data yang dikumpulkan sendiri oleh peneliti langsung dari objeknya, yaitu pada Kantor Akuntan Publik di Sumatera Utara. Pengumpulan data dilakukan dengan cara mengedarkan kuesioner yang disampaikan langsung kepada responden.

\section{Metode Analisis data}

Model analisa data yang digunakan untuk menguji hipotesis adalah regresi linear berganda (Multiple Linear Regression) yang diolah dengan program komputer SPSS (Statistical Package for Social Science). Adapun model regresi dalam penelitian ini adalah:

$$
\mathrm{Y}=\alpha+\beta_{1} \mathrm{X}_{1}+\beta_{2} \mathrm{X}_{2}+\beta_{3} \mathrm{X}_{3}+\mathrm{e}
$$


Keterangan :

$$
\begin{array}{ll}
\mathrm{Y} & =\text { Judgment Auditor } \\
\mathrm{X}_{1} & =\text { Tekanan Ketaatan } \\
\mathrm{X}_{2} & =\text { Materialitas } \\
\mathrm{X}_{3} & =\text { Risiko Audit } \\
\mathrm{B}_{1} \beta_{2} \beta_{3} & =\text { Koefisien } \mathrm{x}_{1} \mathrm{x}_{2} \mathrm{X}_{3} \\
\alpha & =\text { Konstanta } \\
\mathrm{e} & =\text { Error regresi }
\end{array}
$$

\section{Hasil dan Pembahasan}

\section{Hasil Analisi Regresi Linear Berganda}

Untuk mengetahui pengaruh tekanan ketaatan (X1), materialitas (X2) dan risiko audit (X3) terhadap kepatan judgment auditor (Y) pada Kantor Akuntan Publik di Sumatera Utara, baik secara simultan maupun parsial dilakukan dengan menggunakan metode regresi linear berganda (multiplelinear regression) yang diolah dengan SPPS vers 15.0 secara rinci dapat dilihat pada tabel berikut ini:

Tabel 1.

Pengaruh Variabel tekanan Ketaatan, Materialitas, dan Risiko Audit Terhadap

\begin{tabular}{lcc}
\multicolumn{3}{c}{ Judgment Auditor } \\
\hline Nama Variabel & B & Standar Error \\
\hline Konstanta $(\alpha)$ & 2,256 & 0,199 \\
Tekanan & 0,135 & 0,035 \\
Ketaatan & & \\
Materialitas & 0,100 & 0,041 \\
Risiko Audit & 0,202 & 0,040 \\
\hline
\end{tabular}

Dari hasil analisa diperoleh persamaan regresi linear berganda berikut ini:

$$
Y=2,256+0,135 X_{1}+0,100 X_{2}+0,202 X_{3}+€
$$

Berdasarkan hasil pengujian tabel 4.1 diperoleh bahwa semua regresi (B masing-masing variabel independen tidak sama dengan nol $\left(\beta_{1}=0,135\right.$ $\beta_{2}=0,100$ dan $\left.\beta_{3}=0,202\right)$. Dari ketentuan bahawa jika paling sedikit ada satu $\beta_{\mathrm{i}}(\mathrm{I}=1,2$, dan 3$) \neq 0$, maka tekanan ketaatan, materialitas, dan risiko audit secara bersama-sama mempengaruhi ketepatan judgment auditor pada Kantor Akuntan Publik di Sumatera Utara. Hasil ini menolak $\mathrm{H}_{0}$ (hipotesis nol) dan menerima $\mathrm{H}_{\mathrm{A}}$ (hipotesis alternatif).

\section{Koefisien Korelasi (R)}

Koefisien korelasi $(\mathrm{R})=0,793$ menunjukkan bahwa derajat hubungan (korelasi) anatara variabel dependen dengan variabel independen sebesar $79,3 \%$. Artinya peningkatan judgment auditor (Y) sangat kuat dengan faktor tekanan ketaatan $\left(\mathrm{X}_{1}\right)$, materialitas $\left(\mathrm{X}_{2}\right)$, dan risiko audit $\left(\mathrm{X}_{3}\right)$. Karena $\mathrm{R}$ lebih besar dari 0,5. Secara rinci dapat dilihat pada tabel 4.2 berikut ini:

Tabel 2.

Model Summary Pengaruh Variabel Tekanan Ketaatan, Materialitas, dan Risiko Audit Terhadap Ketepatan Judgment Auditor

\begin{tabular}{ccccc}
\hline $\mathbf{R}^{\mathbf{2}}$ & $\begin{array}{c}\mathbf{R} \\
\text { Square } \\
\left(\mathbf{R}^{2}\right)\end{array}$ & $\begin{array}{c}\text { Adjusted } \\
\left(\mathbf{R}^{2}\right)\end{array}$ & $\begin{array}{c}\text { Std. Error } \\
\text { of The } \\
\text { Estismate }\end{array}$ & Keterangan \\
\hline 0,793 & 0,629 & 0,601 & 156 & $\begin{array}{c}\text { Korelasi } \\
\text { Kuat }\end{array}$ \\
\hline
\end{tabular}

\section{Koefisien Determinasi $\left(\mathbf{R}^{2}\right)$}

Koefisien determinasi $\left(R^{2}\right)=0,629$ yang berarti sebesar 62,9\% perubahan-perubahan dalam variabel dependan (judgment auditor) dapat dijelaskan oleh perubahan-perubahan dari faktor tekanan ketaatan, materialitas, dan risiko audit. Hal ini menunjukkan setiap variabel independen mempunyai pengaruh terhadap judgment auditor.

\section{Kesimpulan dan Saran}

Dari hasil pengujian yang telah dilakukan terhadap permasalahanyang dirumuskan dalam hipotesis penelitian dengan menggunakan uji regresi linear berganda mendukung $\mathrm{H}_{1}, \mathrm{H}_{2}, \mathrm{H}_{3}$, dan $\mathrm{H}_{4}$ maka dapat ditarik kesimpulan sebagai berikut:

1. Variabel tekanan ketaatan, materialitas, dan risiko audit secara bersama-sama mempengaruhi ketepatan judgment auditor pada Kantor Akuntan Publik di Sumatera Utara.

2. Secara parsial variabel tekanan ketaatan berpengaruh terhadap ketepatan judgment auditor pada Kantor Akuntan Publik.

3. Secara parsial variabel materialitas berpengaruh terhadap ketepatan judgment auditor pada Kantor Akuntan Publik.

4. Secara parsial variabel risiko audit berpengaruh terhadap ketepatan judgment auditor pada Kantor Akuntan Publik. 
Berdasarkan keterbatasan penelitian diatas, maka peneliti memberikan beberapa saran untuk penelitian selanjutnya sebagai berikut ini:

1. Penelitian mendatang diharapkan dapat memperluas populasipenelitian. Populasi penelitian tidak hanya auditor yang bekerja pada Kantor Akuntan Publik di Sumatera Utara saja, mungkin bisa dikembangkan pada auditor pemerintah yang bekerja pada BPKP, BPK, BAWASDA serta akuntan publik.

2. Bagi peneliti lain yang ingin melakukan penelitian dengan tema yang sama disarankan agar menggunakan butir pertanyaan yang lebih banyak dan lebih bervariasi pada kuesioner yang disebar.

3. Pada KAP diharapkan agar dapat melakukan pengakajian yang lebih mendalam tentang tekanan ketaatan yang dihadapi oleh para auditor dalam menjalankan tugas audit mereka dengan melihat berbagai perseptif terhadap penerapan standar profesional yang ada di Indonesia serta diharapkan bagi para auditor untuk berpegang teguh pada norma dan standar profesional auditor agar dapat menetralisir tindakan-tindakan yang menyimpang dari standar etika yang dapat berakibat pada judgment yang mereka dihasilkan.

\section{Daftar Pustaka}

Adam, O. F., \& Suzan, L. (2015). Pengaruh Pengendalian Internal Terhadap Kecenderungan Kecurangan Akuntansi (studi Kasus Pada Baitul Mal Wa Tamwil Di Kota Salatiga). eProceedings of Management, 2(3).

Agoes, Sukrisno (2004). Auditing (Pemerikasaan Akuntan) oleh Kantor Akuntan Publik. Edisi. 3, Jil. 1. FEUI.
Akadiyantor (2004).
Pengaruh Authoritarianism dan Tekanan Kepatuhan Terhadap Judgment Auitor (Suatu Eksperimen Semu Terhadap Mahasiswa Fakultas Ekonomi Jurusan Akuntansi yang Telah Menempuh Matakuliah Auditing). Skripsi Abstrak.

Arikunto, Suharsimi (2006). Pengaruh Penelitian Suatu Pendekatan Praktisi. Edisi Revisi VI. Jakarta: Rineka Cipta.

Ariningsih, P. S., \& Mertha, I. M. (2017). Pengaruh Independensi, Tekanan Anggaran Waktu, Risiko Audit, dan Gender Pada Kualitas Audit. E-Jurnal Akuntansi Universitas Udayana, 18(2), 1545-1574.

Danny, A. I. (2015). Pengaruh Profesionalisme Dan Independensi Auditor Terhadap Pertimbangan Tingkat Materialitas Salah Saji Laporan Keuangan Instansi Pemerintah (Studi pada Kantor BPKP RI di Jakarta) (Doctoral dissertation, Fakultas Ekonomi Unpas).

Fanny, M., \& Saputra, S. (2005). Opini audit going concern: Kajian berdasarkan model prediksi kebangkrutan, pertumbuhan perusahaan, dan reputasi kantor akuntan publik (studi pada emiten bursa efek Jakarta). Simposium Nasional Akuntansi, 8, 966-978.

Giri, E. F. (2010). Pengaruh Tenur Kantor Akuntan Publik (KAP) dan Reputasi KAP terhadap Kualitas Audit: Kasus Rotasi Wajib Auditor di Indonesia. Simposium Nasional Akuntansi XIII, 1-26.

Hamdani, H., Wahyuni, N., Amin, A., \& Sulfitra, S. (2018). Analisis Faktor-Faktor yang mempengaruhi Kinerja Keuangan Bank Umum Syariah yang terdaftar di Bursa Efek Indonesia (BEI) (Periode 2014-2016). Jurnal EMT KITA, 2(2), 6273.

Handayani, V., Yusralaini, Y., \& Natariasari, R. (2016). Pengaruh TIME Pressure, Risiko Audit, Turnover Intention, Prosedur Review Dan Kontrol Kualitas Terhadap Penghentian Prematur Atas Prosedur Audit (Studi Empiris Pada Auditor Kantor Akuntan Publik Di Pekanbaru, Padang Dan Medan) (Doctoral dissertation, Riau University). 
Herliansyah, Y., \& Ilyas, M. (2006). Pengaruh pengalaman auditor terhadap penggunaan bukti tidak relevan dalam auditor judgment. SNA 9 Padang, 23-26.

Jamilah, S., Z. Fanani dan G. Chandrarin (2007). Pengaruh Gender, Tekanan Ketaatan dan Kompleksitas Tugas Terhadap Audit Judgment. Simposium Nasional Akuntansi X. Makassar.

Lubis, R. H., SE, A., Dewi, R. S., \& SE, S. P. (2020). Pemeriksaan Kuntansi 1 (Auditing 1). Prenada Media.

Meyer, M. dan J. T. Rigsby (2001). Descriptive Analisys of The Content and Contribution of Behavioral Research in Accounting 1989-1998. Accounting Journal.

Mulyadi. (2002). Auditing. Buku 1, Edisi 6. Jakarta: Salemba Empat.

Rajagukguk, T. S. (2017). Faktor Yang Mempengaruhi Keputusan Penerimaan Klien Pada Kantor Akuntan. Owner (Riset dan Jurnal Akuntansi), 1(2), 1-10.
Thahir, T. (2016). Pengaruh Professional Judgment, Independensi, Dan Kompetensi Auditor Terhadap Pertimbangan Tingkat Materialitas Dalam Pengauditan Laporan Keuangan (Survei Pada Kantor BPK RI Perwakilan Provinsi Jawa Barat) (Doctoral dissertation, Universitas Widyatama).

Yendrwati, R., \& Mukti, D. K. (2015). Pengaruh gender, pengalaman auditor, kompleksitas tugas, tekanan ketaatan, kemampuan kerja dan pengetahuan auditor terhadap audit judgement. Asian Journal of Innovation and Entrepreneurship, 4(01), 1-8.

Yenni, E. (2017). Pengaruh Pemahaman Akuntansi dan Pengalaman Kerja Aparatur Terhadap Penyusunan Laporan Keuangan Daerah Pada Pemerintah Kota Banda Aceh. Jurnal EMT KITA, 1(2), 91-96.

Yustrianthe, R. H. (2012). Beberapa faktor yang mempengaruhi audit judgment auditor pemerintah. Jurnal Dinamika Akuntansi, $4(2)$. 